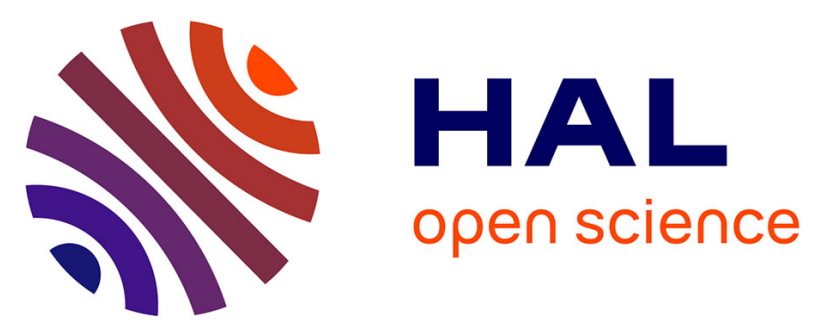

\title{
Relationships between social stigma, stigma experience and self-stigma and impaired quality of life in schizophrenia accross three Latin-America countries
} Alejandra Caqueo-Urízar, Alfonso Urzúa, Julia Habib, Anderson Loundon, Mohamed Boucekine, Laurent Boyer, Guillaume Fond

\section{To cite this version:}

Alejandra Caqueo-Urízar, Alfonso Urzúa, Julia Habib, Anderson Loundon, Mohamed Boucekine, et al.. Relationships between social stigma, stigma experience and self-stigma and impaired quality of life in schizophrenia accross three Latin-America countries. European Archives of Psychiatry and Clinical Neuroscience, 2019, 10.1007/s00406-019-01035-8 . hal-02473666

\section{HAL Id: hal-02473666 \\ https://hal-amu.archives-ouvertes.fr/hal-02473666}

Submitted on 10 Feb 2020

HAL is a multi-disciplinary open access archive for the deposit and dissemination of scientific research documents, whether they are published or not. The documents may come from teaching and research institutions in France or abroad, or from public or private research centers.
L'archive ouverte pluridisciplinaire HAL, est destinée au dépôt et à la diffusion de documents scientifiques de niveau recherche, publiés ou non, émanant des établissements d'enseignement et de recherche français ou étrangers, des laboratoires publics ou privés. 
Relationships between social stigma, stigma experience and self-stigma and impaired quality of life in schizophrenia accross three Latin-America countries.

Alejandra Caqueo-Urízar ${ }^{1}$, Alfonso Urzúa ${ }^{2}$, Julia Habib ${ }^{3}$, Anderson Loundon ${ }^{3}$, Mohamed Boucekine $^{3}, \&$ Laurent Boyer ${ }^{3}$, Guillaume Fond ${ }^{3}$

${ }^{1}$ Instituto de Alta Investigación, Universidad de Tarapacá. Arica, Chile.

${ }^{2}$ Universidad Católica del Norte. Avda. Angamos 0610, Antofagasta, Chile. Email: alurzua@ucn.cl

${ }^{3}$ Aix-Marseille Univ, EA 3279 - Public Health, Chronic Diseases and Quality of Life Research Unit, 13005 Marseille, France.

\section{* Corresponding author}

Dr Guillaume Fond

Aix-Marseille Univ, School of medicine - La Timone Medical Campus, EA 3279: CEReSS Health Service Research and Quality of Life Center, 27 Boulevard Jean Moulin, 13005 Marseille, France

guillaume.fond@ap-hm.fr 


\begin{abstract}
(limited 250)
Background. The relationships between stigma and quality of life in schizophrenia (QoL) have been extensively explored but have mostly focused on self-stigma and self-esteem and have never been explored in Latin-America.
\end{abstract}

Objective. To determine which stigma dimensions were associated with QoL in a sample of community dwelling SZ subjects of three Latin-America countries.

Methods. Stabilized outpatients with SZ were recruited in 3 Mental Health Services in three Latin American countries: Bolivia $(\mathrm{N}=83)$, Chile $(\mathrm{N}=85)$ and Peru $(\mathrm{N}=85)$. Stigma and Qol-SZ were evaluated by self-administered questionnaires, the Internalized Stigma of Mental Illness scale (ISMI-12) and the SQoL-18.

Results. 253 participants were included. In multivariate analyses, QoL has been associated with each stigma dimension (social stigma, stigma experience and self-stigma), independently of age, gender, education level, ethnicity, age at illness onset, illness symptomatology and mental health treatment. More specifically, social stigma was significantly associated with impaired psychological and physical well-being, self-esteem and friendship. Self-stigma was significantly associated with impaired psychological well-being, self-esteem and autonomy.

Conclusion. The present results confirm the importance of stigma in QoL of SZ subjects and identify new targets to develop stigma-orientated programs. Most of the previous programs have focused on self-stigma while social stigma has shown to be associated with a wide range of impaired QoL areas. Stigma and QoL may have a bidirectional relationship and targeting some specific QoL areas (like autonomy through self-empowerment approaches) may also improve the effectiveness of these programs to reduce stigma impact on the quality of life of subjects with schizophrenia. Future studies should also explore differences across countries as subjects from Bolivia were more frequently Aymara and reported higher stigma and lower QoL than SZ subjects from other countries.

Keywords: Stigma, schizophrenia, quality of life, well-being. 


\section{Introduction}

Schizophrenia is the mental disorder that is the most associated with stigma in general populations around the world [1]. People with a schizophrenia-spectrum diagnosis experience higher levels of stigma compared to any other mental health diagnosis [2, 3]. The findings of a systematic review by Gerlinger and colleagues (2013) indicate that from one-third to onehalf of patients with schizophrenia (SZ) feels shame as a consequence of the disorder [4]. Stigma is also a barrier for early antipsychotic treatment onset, and increased duration of untreated psychosis has been associated with worse prognosis [5].

Beyond illness course, stigma has also been extensively associated with impaired quality of life (QoL) in SZ in multiple countries covering mostly Asia, some European and African countries and the USA [1, 6-14, 14-37]. No study has been carried out in LatinAmerica countries to date, while society plays a major role in stigma experience [38].

Moreover, the previous studies have mostly explored the specific association of selfstigma with impaired self-esteem in a purpose of developing self-stigma targeted interventions. These interventions have shown promising preliminary results [3]. Exploring the multiple dimensions of stigma may improve the effectiveness of these interventions. Most of the existing stigma instruments explored three stigma dimensions: perceived/social stigma (defined by the social dimension of stigma, i.e. being side-lined by mentally healthy people), experienced stigma (defined by the subjective feeling of experiencing discrimination) and self-stigma (defined by "internalization of public stigma" or as "the product of internalization of shame, blame, hopelessness, guilt and fear of discrimination associated with mental illness") [39-41]. We confirmed these three dimensions in a recent study validating the ISMI12 scale [42]. 
The aim of this study was to determine which stigma dimensions were associated with QoL in a sample of stabilized community dwelling SZ subjects of three Latin-America countries.

\section{Methods}

Study participants

SZ outpatients were consecutively recruited between May 2012 and February 2013 in the three public ambulatory psychiatric care centers of three areas: Arica, northern Chile $(\mathrm{N}=85,33.6 \%)$, Tacna, southern of Peru $(\mathrm{N}=85,33.6 \%)$, and La Paz, Central-Western of Bolivia $(\mathrm{N}=83,32.8 \%)$. The three centers shared similar characteristics in terms of size, type of treatment delivered to patients, professionals and free access of care.

\section{Inclusion criteria}

All stabilized community-dwelling patients diagnosed with schizophrenia according to the criteria of International Classification of Diseases (ICD), $10^{\text {th }}$ version were included in this study. Schizophrenia diagnosis was confirmed within a standardized interview. Stabilization was defined by the absence of current acute psychotic episode at the time of evaluation and absence of ongoing change in pharmacological treatment in the last 2 months.

\section{Exclusion criteria}

Patients with a history of neurological disorders (including stroke, epilepsy and head injury) or all illnesses affecting central nervous system were not included in the present study.

\section{Procedures}

Two psychologists, who were part of the research team, trained for scale evaluation, and supervised by the principal researcher (ACU), conducted the evaluations of the participants under the auspices of the mental health services of each country. The length of time of the evaluation was between 20-30 minutes. 


\section{Stigma assessment}

The Internalized Stigma of Mental Illness scale (ISMI-12) [42] is the short form of one of the most widely used measurements of internalized stigma in mental health research, the ISMI-29 (Ritsher, Otilingam \& Grajales, 2003; Ritsher \& Phelan, 2004; Lysaker, Roe \& Yanos, 2007; Boyd, Adler, Otilingam \& Peters, 2014). The dimensions were named according to their constitutive items: social stigma (4 items), stigma experience (4 items), and self-stigma (3 items). The 12 items are detailed in the Appendix. The three dimensions were independent based on principal component factor analyses with varimax rotation. A higher score was associated with higher self-reported stigma in each dimension.

Quality of life

QoL was assessed using the shortened questionnaire to assess quality of life in schizophrenia (S-QoL18), a self-administered QoL questionnaire designed for people with schizophrenia [43] and validated in Latin America [44]. The S-QoL-index ranges from 0, indicating the lowest QoL, to 100, the highest QoL. Eight dimensions are explored in this scale: PsW: psychological well-being; SE: Self-Esteem; RFa: family relationships; RFr: relationships with friends; RE: resilience; PhW: physical well-being; AU: autonomy; SL: sentimental life. The items of each dimension are described in the Appendix.

\section{Demographic and illness characteristics variables}

Age, gender, ethnicity (Aymara and non-Aymara), marital status (with or without partner), educational level $(\geq 12$ years or $<12$ ), illness duration, family income (measure of the total salary per month for all members of the family, expressed in US dollars), and age at illness onset were reported. Concerning ethnicity, the Aymara is the largest ethnic group in the region, with a population of 2 million people, and has lived in the Andes Mountains for centuries. Recent generations of Aymara have undertaken a massive migration from rural 
towns to large cities and, thus, receive healthcare services from the same clinics as nonAymara individuals [45].

Current symptomatology was evaluated with the Positive and Negative Syndrome scale for Schizophrenia (PANSS)[46]. This 30-item, 7-point (1-7) rating scale has been specifically developed to assess current symptomatology in SZ individuals. The 3-factors structure (positive factor, negative factor and general psychopathology) was used. The PANSS has been translated and validated in Spanish [47]. All patients were administered antipsychotics. The presence or absence of add-on integrated treatment (defined by psychotherapy, family psychoeducation, and/or day care hospital in addition to pharmacological treatment) were also reported.

\section{Ethical considerations}

Before the start of the study, written informed consent was requested and received from the patient and her/his primary caregiver. The objectives of the study were explained as well as the voluntary nature of participation. No compensation was offered for participating in the study. The study was approved by the Ethics Committee of the University of Tarapacá and the National Health Service of Chile.

\section{Statistical analysis}

Associations between QoL scores and the continuous variables (social stigma, stigma experience, self-stigma, age, family income, age at illness onset, illness duration, symptom severity) were analyzed using Pearson's correlation tests. Means-based comparisons of the SQo18 index between various subgroups (men vs. women, high vs. low education level, Aymara vs. Non-Aymara, pharmacological vs. pharmacological + non pharmacological/integrated treatment) were calculated using Student $\mathrm{t}$ tests. 
Multivariate analyses using multiple linear regression (simultaneous model) were then performed to determine variables potentially associated with QoL levels. The S-QoL 18 index and each of its dimensions were considered as separate dependent variables. The variables relevant to the models were selected from the univariate S-QoL18 index analysis based on a threshold $p$-value $\leq 0.20$. Gender was included in the models because of its sociodemographic interest.

The final models incorporated the standardized $B$ coefficients, which represent a change in the standard deviation of the dependent variable (QoL) resulting from a change of one standard deviation in the various independent variables. The independent variables with the higher standardized beta coefficients are those with a greater relative effect on QoL.

This study was a confirmatory analysis. No correction for multiple testing has therefore been carried out, which is consistent with recommendations [48]. All the tests were two-sided. Statistical significance was defined as $\mathrm{p}<0.05$. The statistical analyses were performed using the SPSS version 20.0 software package (SPSS Inc., Chicago, IL, USA).

\section{Results}

Overall, 253 community-dwelling SZ patients were recruited in the present study, with a mean age of 35.6 years, $164(66.4 \%)$ men and a mean illness duration of 14.6 years. The characteristics of the sample are presented in Table 1. Differences across countries are presented in Supplementary table 1. The rate of Aymara subjects was higher in Bolivia compared to Chile and Peru (57.8\% vs. $36.5 \%$ and $44.7 \%$ respectively).

In univariate analyses, decreased S-Qol index was associated with all stigma level dimensions (social stigma $\mathrm{R}=-0.38, \mathrm{p}<0.001$, stigma experience, $\mathrm{R}=-0.47, \mathrm{p}<0.001$, selfstigma $\mathrm{R}=-0.42, \mathrm{p}<0.001$ ), current illness severity (PANSS total score $\mathrm{R}=-0.37, \mathrm{p}<0.001$ ), ethnicity (Aymara vs. non-Aymara 52.27 vs. 55.97, $\mathrm{p}=0.042$ ), education level ( $\geq 12$ years VS. $<12$ years: 52.70 vs. $62.47, \mathrm{p}<0.001)$. In multivariate analyses, QoL has been associated with 
each stigma dimension (social stigma, stigma experience and self-stigma), independently of age, age at illness onset, illness symptomatology (PANSS score), gender, education level, ethnicity, and mental health treatment (Table 2).

More specifically, social stigma was significantly associated with impaired psychological and physical well-being, self-esteem and relationships with friends. Self-stigma was significantly associated with impaired psychological well-being, self-esteem and autonomy. Stigma experience was only associated with impaired sentimental life. None of the stigma dimension was associated with impaired resilience.

\section{Discussion}

Altogether, the results of the present study may be summarized as follows: in a sample of stabilized community dwelling SZ subjects of 3 Latin-America countries, stigma was associated with impaired QoL. The associations between impaired QoL and stigma varied according to each stigma dimension. Impaired psychological well-being and self-esteem were both associated with social- and self-stigma. Social stigma was specifically associated with impaired physical well-being and friendship, while self-stigma was associated with impaired autonomy and stigma experience with impaired sentimental life.

Our results have confirmed that stigma is associated with impaired QoL in stabilized SZ subjects in Latin-America countries. This association has been consistently reported across the world and for the first time in Latin-America countries, suggesting that schizophrenia appears as a specific mental illness that provides high stigma levels whatever the society, cultural beliefs or global education level. This phenomenon was recently highlighted in a French/German study exploring the impact of the term "schizophrenia" as well as the symptoms of the illness as sources of stigma in the general population [49]. Given that our 
study is the first to use the ISMI-12 scale to evaluate stigma, no direct comparison with other studies carried out in other countries could be done, which is a limit of the present results.

The association between self-stigma and impaired self-esteem has been confirmed in the present study, consistently with previous studies $[9,17,31,32,50,51]$. Beyond this association, we have also found that self-stigma was also associated with impaired psychological well-being and impaired autonomy. No study has specifically explored the association between stigma and autonomy in schizophrenia to date. Òn the contrary, recovery has been extensively shown to be associated with improved stigma in SZ subjects [52-54]. The association between self-stigma and impaired autonomy may be mediated by cognitive deficits $[18,25,26]$ or social anxiety [17] that were previously found to be associated with self-stigma but that have not been explored here, which is a limitation of the present work. Self-stigma and impaired autonomy may have a bidirectional relationship, targeting both selfstigma (by specific cognitive behavioral interventions) as well as autonomy (by recovery/psychosocial interventions) may therefore improve the psychological well-being of SZ subjects.

Our results suggest that social stigma was also associated with impaired self-esteem and psychological well-being in subjects with schizophrenia. Social stigma is the feeling of being sidelined from the mentally healthy people while internalized stigma is the feeling of deserving it. The stigma-orientated interventions may therefore target not only the feeling of deserving isolation but directly some beliefs underpinning social stigma. For example, patients experiencing social stigma report that having mental illness makes them need other to make decision for them, that mentally healthy people cannot understand them or that they need to stay away from social situations to protect their relatives from embarrassment. These beliefs may be directly targeted by cognitive behavioral interventions. Acceptance and commitment therapy may be particularly suitable psychotherapy for these patients [55]. This 
third wave cognitive behavioral therapy includes mindfulness, acceptance and compassion that may specifically improve stigma in SZ subjects [56].

Altogether, our results suggest that social stigma and self-stigma are associated with a wider range of impaired QoL areas than stigma experience. Those reporting high level of stigma experience in our study reported also impaired levels of sentimental QoL. Sentimental life has been poorly explored in schizophrenia to date [57], this area of QoL should be specifically explored in future studies.

Limits. The present data is cross-sectional and longitudinal studies may yield relevant insight on the mechanisms of the association between stigma and QoL in SZ subjects. Selfperceived cognitive deficits have been associated with both QoL of SZ subjects and stigma and have not been explored in the present study. Stigma resistance, i.e. the capacity to resist to stigma [27] and the specific issue of job seeking [33] have also not been explored. Subjects from Bolivia were more frequently Aymara, which may explain the lower QoL score and higher stigma levels reported in this country. Future studies with larger samples should be carried out to examine country differences and their impact on stigma in SZ subjects.

Strengths. The use of standardized questionnaires and the inclusion of important confounding factors may be mentioned in the strengths of the present study. The impact of stigma on SZ QoL has been explored for the first time in Peru, Bolivia and Chile. Psychotherapy has been taken into account in our analyses, which had not been done in most of the previous studies.

Perspectives. Different interventions have been explored to reduce stigma in schizophrenia. Some countries have renamed schizophrenia to diminish its associated stigma, however with little evidence for effectiveness [58]. The impact of social media on stigma remains also insufficiently explored $[38,59]$. A recent review has shown small to medium 
effects of contact interventions, educational interventions, mixed contact and education, family psychoeducation programs, and hallucination simulations and has concluded that it was needed to understand the active ingredients of these interventions to improve their effectiveness [60]. Another review has shown the lack of data on the impact of biogenetic causal beliefs on stigma [61]. In summary, further studies are needed to improve stigma coping in SZ subjects and as a consequence their QoL. As patient sociodemographic and illness factors may influence healthcare satisfaction and experience of care [62], future studies should also explore if stigma may impact patients' healthcare satisfaction and experience of care [63].

\section{Conclusion}

Social stigma and self-stigma are associated with a wide range of QoL areas including impaired self-esteem and psychological well-being. Impaired autonomy has also been specifically associated with self-stigma. Each stigma dimension relies on beliefs that should be specifically targeted in stigma-orientated cognitive and behavioral interventions to improve the QoL of SZ subjects.

Conflicts of interest: no conflict to disclose.

Funding. This research was funded in part by the Universidad de Tarapacá through Proyecto Mayor de Investigación Cientí\&\#64257;ca y Tecnológica UTA no. 3732-16. 


\section{References}

1. Holubova M, Prasko J, Matousek S, et al (2016) Comparison of self-stigma and quality of life in patients with depressive disorders and schizophrenia spectrum disorders - a crosssectional study. Neuropsychiatr Dis Treat 12:3021-3030.

https://doi.org/10.2147/NDT.S121556

2. Mestdagh A, Hansen B (2014) Stigma in patients with schizophrenia receiving community mental health care: a review of qualitative studies. Soc Psychiatry Psychiatr Epidemiol 49:79-87. https://doi.org/10.1007/s00127-013-0729-4

3. Wood L, Byrne R, Varese F, Morrison AP (2016) Psychosocial interventions for internalised stigma in people with a schizophrenia-spectrum diagnosis: A systematic narrative synthesis and meta-analysis. Schizophr Res 176:291-303.

https://doi.org/10.1016/j.schres.2016.05.001

4. Gerlinger G, Hauser M, De Hert M, et al (2013) Personal stigma in schizophrenia spectrum disorders: a systematic review of prevalence rates, correlates, impact and interventions. World Psychiatry Off J World Psychiatr Assoc WPA 12:155-164. https://doi.org/10.1002/wps.20040

5. Fond G, Boyer L, Andrianarisoa M, et al (2017) Risk factors for increased duration of untreated psychosis. Results from the FACE-SZ dataset. Schizophr Res. https://doi.org/10.1016/j.schres.2017.08.058

6. Allerby K, Sameby B, Brain C, et al (2015) Stigma and Burden Among Relatives of Persons With Schizophrenia: Results From the Swedish COAST Study. Psychiatr Serv Wash DC 66:1020-1026. https://doi.org/10.1176/appi.ps.201400405

7. Barber JA, Palmese L, Reutenauer EL, et al (2011) Implications of weight-based stigma and self-bias on quality of life among individuals with schizophrenia. J Nerv Ment Dis 199:431-435. https://doi.org/10.1097/NMD.0b013e318221403d

8. Cai C, Yu L (2017) Quality of Life in Patients With Schizophrenia in China: Relationships Among Demographic Characteristics, Psychosocial Variables, and Symptom Severity. J Psychosoc Nurs Ment Health Serv 55:48-54. https://doi.org/10.3928/0279369520170627-03

9. Cavelti M, Kvrgic S, Beck E-M, et al (2012) Self-stigma and its relationship with insight, demoralization, and clinical outcome among people with schizophrenia spectrum disorders. Compr Psychiatry 53:468-479. https://doi.org/10.1016/j.comppsych.2011.08.001

10. Gerlinger G, Hauser M, De Hert M, et al (2013) Personal stigma in schizophrenia spectrum disorders: a systematic review of prevalence rates, correlates, impact and interventions. World Psychiatry Off J World Psychiatr Assoc WPA 12:155-164. 
https://doi.org/10.1002/wps.20040

11. Hasson-Ohayon I, Mashiach-Eizenberg M, Elhasid N, et al (2014) Between self-clarity and recovery in schizophrenia: reducing the self-stigma and finding meaning. Compr Psychiatry 55:675-680. https://doi.org/10.1016/j.comppsych.2013.11.009

12. Holubova M, Prasko J, Latalova K, et al (2016) Are self-stigma, quality of life, and clinical data interrelated in schizophrenia spectrum patients? A cross-sectional outpatient study. Patient Prefer Adherence 10:265-274. https://doi.org/10.2147/PPA.S96201

13. Hsiao C-Y, Lu H-L, Tsai Y-F (2018) Effect of family sense of coherence on internalized stigma and health-related quality of life among individuals with schizophrenia. Int J Ment Health Nurs 27:138-146. https://doi.org/10.1111/inm.12302

14. Kunikata H, Mino Y, Nakajima K (2005) Quality of life of schizophrenic patients living in the community: the relationships with personal characteristics, objective indicators and self-esteem. Psychiatry Clin Neurosci 59:163-169. https://doi.org/10.1111/j.14401819.2005.01352.x

15. Li J, Guo Y-B, Huang Y-G, et al (2017) Stigma and discrimination experienced by people with schizophrenia living in the community in Guangzhou, China. Psychiatry Res 255:225-231. https://doi.org/10.1016/j.psychres.2017.05.040

16. Lv Y, Wolf A, Wang X (2013) Experienced stigma and self-stigma in Chinese patients with schizophrenia. Gen Hosp Psychiatry 35:83-88.

https://doi.org/10.1016/j.genhosppsych.2012.07.007

17. Lysaker PH, Yanos PT, Outcalt J, Roe D (2010) Association of stigma, self-esteem, and symptoms with concurrent and prospective assessment of social anxiety in schizophrenia. Clin Schizophr Relat Psychoses 4:41-48. https://doi.org/10.3371/CSRP.4.1.3

18. Lysaker PH, Vohs JL, Tsai J (2009) Negative symptoms and concordant impairments in attention in schizophrenia: associations with social functioning, hope, self-esteem and internalized stigma. Schizophr Res 110:165-172.

https://doi.org/10.1016/j.schres.2009.01.015

19. Mosanya TJ, Adelufosi AO, Adebowale OT, et al (2014) Self-stigma, quality of life and schizophrenia: An outpatient clinic survey in Nigeria. Int J Soc Psychiatry 60:377-386. https://doi.org/10.1177/0020764013491738

20. Ow C-Y, Lee B-O (2015) Relationships between perceived stigma, coping orientations, self-esteem, and quality of life in patients with schizophrenia. Asia Pac J Public Health 27:NP1932-1941. https://doi.org/10.1177/1010539512469246

21. Paraskevoulakou A, Vrettou K, Pikouli K, et al (2017) Mental Illness Related Internalized Stigma: Psychometric Properties of the Brief ISMI Scale in Greece. Mater Socio- 
Medica 29:211-215. https://doi.org/10.5455/msm.2017.29.211-215

22. Park SG, Bennett ME, Couture SM, Blanchard JJ (2013) Internalized stigma in schizophrenia: relations with dysfunctional attitudes, symptoms, and quality of life. Psychiatry Res 205:43-47. https://doi.org/10.1016/j.psychres.2012.08.040

23. Picco L, Pang S, Lau YW, et al (2016) Internalized stigma among psychiatric outpatients: Associations with quality of life, functioning, hope and self-esteem. Psychiatry Res 246:500-506. https://doi.org/10.1016/j.psychres.2016.10.041

24. Rayan A, Obiedate K (2017) The Correlates of Quality of Life Among Jordanian Patients With Schizophrenia. J Am Psychiatr Nurses Assoc 23:404-413. https://doi.org/10.1177/1078390317710498

25. Savilla K, Kettler L, Galletly C (2008) Relationships between cognitive deficits, symptoms and quality of life in schizophrenia. Aust N Z J Psychiatry 42:496-504. https://doi.org/10.1080/00048670802050512

26. Shin Y-J, Joo Y-H, Kim J-H (2016) Self-perceived cognitive deficits and their relationship with internalized stigma and quality of life in patients with schizophrenia. Neuropsychiatr Dis Treat 12:1411-1417. https://doi.org/10.2147/NDT.S108537

27. Sibitz I, Unger A, Woppmann A, et al (2011) Stigma resistance in patients with schizophrenia. Schizophr Bull 37:316-323. https://doi.org/10.1093/schbul/sbp048

28. Sibitz I, Amering M, Unger A, et al (2011) The impact of the social network, stigma and empowerment on the quality of life in patients with schizophrenia. Eur Psychiatry J Assoc Eur Psychiatr 26:28-33. https://doi.org/10.1016/j.eurpsy.2010.08.010

29. Sibitz I, Friedrich ME, Unger A, et al (2013) [Internalized Stigma of Schizophrenia: Validation of the German Version of the Internalized Stigma of Mental IIIness-Scale (ISMI)]. Psychiatr Prax 40:83-91. https://doi.org/10.1055/s-0032-1332878

30. Staring ABP, Van der Gaag M, Van den Berge M, et al (2009) Stigma moderates the associations of insight with depressed mood, low self-esteem, and low quality of life in patients with schizophrenia spectrum disorders. Schizophr Res 115:363-369.

https://doi.org/10.1016/j.schres.2009.06.015

31. Świtaj P, Grygiel P, Chrostek A, et al (2017) The relationship between internalized stigma and quality of life among people with mental illness: are self-esteem and sense of coherence sequential mediators? Qual Life Res Int J Qual Life Asp Treat Care Rehabil 26:2471-2478. https://doi.org/10.1007/s11136-017-1596-3

32. Tang I-C, Wu H-C (2012) Quality of life and self-stigma in individuals with schizophrenia. Psychiatr Q 83:497-507. https://doi.org/10.1007/s11126-012-9218-2 
33. Thornicroft G, Brohan E, Rose D, et al (2009) Global pattern of experienced and anticipated discrimination against people with schizophrenia: a cross-sectional survey. Lancet Lond Engl 373:408-415. https://doi.org/10.1016/S0140-6736(08)61817-6

34. Tseng C-J, Chiou J-Y, Yen W-J, et al (2012) [Associations between stigma perception and stigma coping behavior and quality of life in schizophrenic patients treated at a community rehabilitation center]. Hu Li Za Zhi 59:62-70. https://doi.org/10.6224/JN.59.3.62

35. Üçok A, Karadayı G, Emiroğlu B, Sartorius N (2013) Anticipated discrimination is related to symptom severity, functionality and quality of life in schizophrenia. Psychiatry Res 209:333-339. https://doi.org/10.1016/j.psychres.2013.02.022

36. Wang XQ, Petrini MA, Morisky DE (2017) Predictors of quality of life among Chinese people with schizophrenia. Nurs Health Sci 19:142-148. https://doi.org/10.1111/nhs.12286

37. Zhang T-M, Wong IY-L, Yu Y-H, et al (2018) An integrative model of internalized stigma and recovery-related outcomes among people diagnosed with schizophrenia in rural China. Soc Psychiatry Psychiatr Epidemiol. https://doi.org/10.1007/s00127-018-1646-3

38. Fond G, Capdevielle D (2011) Psychiatry has to take care of its image on-screen. Prim Care Companion CNS Disord 13:. https://doi.org/10.4088/PCC.11l01145

39. Caqueo-Urízar A, Boyer L, Urzúa A, Williams DR (2019) Self-stigma in patients with schizophrenia: a multicentric study from three Latin-America countries. Soc Psychiatry Psychiatr Epidemiol. https://doi.org/10.1007/s00127-019-01671-4

40. Corrigan PW, Watson AC (2002) Understanding the impact of stigma on people with mental illness. World Psychiatry Off J World Psychiatr Assoc WPA 1:16-20

41. Brohan E, Slade M, Clement S, Thornicroft G (2010) Experiences of mental illness stigma, prejudice and discrimination: a review of measures. BMC Health Serv Res 10:80. https://doi.org/10.1186/1472-6963-10-80

42. Caqueo-Urizar A; Urzua A, Fond $G$, Boyer $L$ The Latin-America version of the Internalized Stigma of Mental Illness scale (LA-ISMI): A multicentric validation study from three Latin-America countries. submitted

43. Boyer L, Simeoni M-C, Loundou A, et al (2010) The development of the S-QoL 18: a shortened quality of life questionnaire for patients with schizophrenia. Schizophr Res 121:241-250

44. Caqueo-Urízar A, Boyer L, Boucekine M, Auquier P (2014) Spanish cross-cultural adaptation and psychometric properties of the Schizophrenia Quality of Life short-version questionnaire (SQoL18) in 3 middle-income countries: Bolivia, Chile and Peru. Schizophr Res 159:136-143. https://doi.org/10.1016/j.schres.2014.08.013 
45. Caqueo-Urízar A, Boyer L, Gilman SE (2017) Needs of Patients with Schizophrenia Among an Ethnic Minority Group in Latin America. J Immigr Minor Health 19:606-615. https://doi.org/10.1007/s10903-016-0376-4

46. Kay SR, Fiszbein A, Opler LA (1987) The positive and negative syndrome scale (PANSS) for schizophrenia. Schizophr Bull 13:261-276

47. Fresán A, De la Fuente-Sandoval C, Loyzaga C, et al (2005) A forced five-dimensional factor analysis and concurrent validity of the Positive and Negative Syndrome Scale in Mexican schizophrenic patients. Schizophr Res 72:123-129.

https://doi.org/10.1016/j.schres.2004.03.021

48. Bender R, Lange S (2001) Adjusting for multiple testing - when and how? J Clin Epidemiol 54:343-349. https://doi.org/10.1016/S0895-4356(00)00314-0

49. Berna F, Göritz AS, Llorca P-M, et al (2017) Would I take antipsychotics, if I had psychotic symptoms? Examining determinants of the decision to take antipsychotics. Prog Neuropsychopharmacol Biol Psychiatry 77:155-163.

https://doi.org/10.1016/j.pnpbp.2017.03.015

50. Guo Y, Qu S, Qin H (2018) Study of the relationship between self-stigma and subjective quality of life for individuals with chronic schizophrenia in the community. Gen Psychiatry 31:e100037. https://doi.org/10.1136/gpsych-2018-100037

51. Lien Y-J, Chang H-A, Kao Y-C, et al (2018) The impact of cognitive insight, self-stigma, and medication compliance on the quality of life in patients with schizophrenia. Eur Arch Psychiatry Clin Neurosci 268:27-38. https://doi.org/10.1007/s00406-017-0829-3

52. Pernice FM, Biegel DE, Kim J-Y, Conrad-Garrisi D (2017) The mediating role of mattering to others in recovery and stigma. Psychiatr Rehabil J 40:395-404. https://doi.org/10.1037/prj0000269

53. Ivezić SŠ, Sesar MA, Mužinić L (2017) Effects of a Group Psychoeducation Program on Self-Stigma, Empowerment and Perceived Discrimination of Persons with Schizophrenia. Psychiatr Danub 29:66-73

54. Norman RMG, Li Y, Sorrentino R, et al (2017) The differential effects of a focus on symptoms versus recovery in reducing stigma of schizophrenia. Soc Psychiatry Psychiatr Epidemiol 52:1385-1394. https://doi.org/10.1007/s00127-017-1429-2

55. Ducasse D, Fond G (2013) [Acceptance and commitment therapy.]. L'Encephale. https://doi.org/10.1016/j.encep.2013.04.017

56. Louise S, Fitzpatrick M, Strauss C, et al (2018) Mindfulness- and acceptance-based interventions for psychosis: Our current understanding and a meta-analysis. Schizophr Res 192:57-63. https://doi.org/10.1016/j.schres.2017.05.023 
57. Andrianarisoa M, Boyer L, Godin O, et al (2017) Childhood trauma, depression and negative symptoms are independently associated with impaired quality of life in schizophrenia. Results from the national FACE-SZ cohort. Schizophr Res 185:173-181. https://doi.org/10.1016/j.schres.2016.12.021

58. Yamaguchi S, Mizuno M, Ojio Y, et al (2017) Associations between renaming schizophrenia and stigma-related outcomes: A systematic review. Psychiatry Clin Neurosci 71:347-362. https://doi.org/10.1111/pcn.12510

59. Ross AM, Morgan AJ, Jorm AF, Reavley NJ (2019) A systematic review of the impact of media reports of severe mental illness on stigma and discrimination, and interventions that aim to mitigate any adverse impact. Soc Psychiatry Psychiatr Epidemiol 54:11-31. https://doi.org/10.1007/s00127-018-1608-9

60. Morgan AJ, Reavley NJ, Ross A, et al (2018) Interventions to reduce stigma towards people with severe mental illness: Systematic review and meta-analysis. J Psychiatr Res 103:120-133. https://doi.org/10.1016/j.jpsychires.2018.05.017

61. Larkings JS, Brown PM (2018) Do biogenetic causal beliefs reduce mental illness stigma in people with mental illness and in mental health professionals? A systematic review. Int J Ment Health Nurs 27:928-941. https://doi.org/10.1111/inm.12390

62. Ratner $Y$, Zendjidjian XY, Mendyk N, et al (2018) Patients' satisfaction with hospital health care: Identifying indicators for people with severe mental disorder. Psychiatry Res 270:503-509. https://doi.org/10.1016/j.psychres.2018.10.027

63. Knaak S, Mantler E, Szeto A (2017) Mental illness-related stigma in healthcare: Barriers to access and care and evidence-based solutions. Healthc Manage Forum 30:111116. https://doi.org/10.1177/0840470416679413 